Elsevier

JIM 04398

\title{
A semi-automated fluorescent (SAF) assay using viable, whole cells for screening hybridoma supernatants *
}

\author{
M. Liebert, L. Laino and R.L. Wahl \\ Division of Nuclear Medicine, Department of Internal Medicine, University of Michigan Medical Center, Ann Arbor, MI, U.S.A.
}

(Received 16 January 1987, accepted 9 March 1987)

In the production of monoclonal antibodies, a rapid, sensitive, accurate assay is needed for the critical step of screening. We report the modification of an assay using viable whole cells for screening hybridoma supernatants. The modified assay uses fluorescent second antibodies for detection and has been adapted to an instrument capable of automating a number of assay steps. The modified assay is compared to a dot radioimmunoassay developed and used in our laboratory. The fluorescence assay is highly sensitive but shows more background effect, especially in samples with high protein content, such as ascites. The automated fluorescence assay is very rapid, capable of completing an assay in less than 90 min, and can be performed with minimal operator involvement. The assay was performed successfully with several different antibodies and cell types. This screening procedure should be especially useful for laboratories with large numbers of fusions to evaluate.

Key words: Monoclonal antibody; Hybridoma screening procedure; Immunofluorescence

\section{Introduction}

One of the most time-consuming and labor-intensive steps in the production of monoclonal antibodies is the screening. Screening is a critical step in the development of monoclonal antibodies of desired specificity, because screening results are used to determine which cells will be subcloned and saved. Time is also a limiting factor because of cell growth while waiting for results. Therefore, the assay chosen must be accurate, fast, sensitive,

Correspondence to: R.L. Wahl, Division of Nuclear Medicine, University of Michigan Medical Center, 1500 Medical Center Drive, Box 0028, Ann Arbor, MI 48109-0028, U.S.A.

* Supported in part by PHS R01-CA40497-02, R01-CA4153102, R01-CA33802 awarded by NCI, DHHS, and by DOE Contract DE-AC02-76EV002031. inexpensive, and capable of handling many samples at once (Goding, 1980; Eshhar, 1985).

Many techniques have been developed for screening monoclonal antibodies, such as ELISAs, radioimmunoassays, and fluorescent assays (e.g. Goding, 1980; Howard et al., 1980; Kennett, 1980; Glassy et al., 1983; Furst and Mahowald, 1984; Stya et al., 1984; Eshhar, 1985; Hough et al., 1986; Okumura et al., 1986; and others). For production of antibodies likely to be useful for tumor imaging and therapy, target antigens must be accessible on the tumor cell surface in situ. For this purpose, we previously developed an assay that detected antigens on the surface of whole live cells (Stya et al., 1984). We here report the development and use of a fluorescent assay that uses whole live cells for screening hybridomas in an instrument capable of automating a number of assay steps. Automation greatly reduces the labor 
and time involved in screening hybridomas. This report describes our optimization of the technique and compares it to the 'dot radioimmunobinding' (DRIB) assay previously described (Stya et al., 1984).

\section{Materials and methods}

\section{Antibodies}

The antibodies used in these experiments include $5 \mathrm{G} 6.4$, a murine monoclonal IgG antibody prepared in this laboratory that has specificity for ovarian cancer (Wahl et al., 1986). An antimelanoma antibody, 225.28S (IgG2a) has been previously described (Wilson et al., 1983). $6 \mathrm{~g} 10$ is directed against an antigen on small cell carcinoma of the lung and was prepared in this laboratory (Stya, unpublished). Purified antibodies were prepared from ascites using chromatography (staphylococcal protein A (SpA) for IgG2a and DEAE for IgG1 (Ey et al., 1970; Goding, 1980, respectively)). Purified UPC-10 was purchased (Organon Teknika Corp., Irving, TX). Affinity-purified second antibodies, rabbit anti-mouse IgG, and fluorescein-isothiocyanate (FITC)-conjugated goat anti-mouse IgG, A and M, were purchased (Cappel, Malvern, PA; Kirkegaard and Perry, Gaithersburg, MD).

\section{Cell Lines}

The cell lines used include HTB 77, human ovarian cancer, the human melanoma lines HTB 66 and 63 , and human small cell carcinoma of the lung NCI 69; all cell lines were obtained from ATCC, Rockville, MD. Viability was evaluated by staining with fluorescein diacetate, as previously described (Rotman and Papermaster, 1966; Jones and Senft, 1985).

\section{Assays}

The dot-radioimmunobinding assay (DRIB) was performed as previously described (Stya et al., 1984), with slight modifications. Briefly, the assay is performed as follows: 96-well plates with membrane bottoms (Millipore) are blocked with DRIB buffer (2\% BSA, 1\% EDTA in $0.01 \mathrm{M}$ phosphate-buffered saline (PBS), $\mathrm{pH} 7.2$, overnight at $4{ }^{\circ} \mathrm{C}$ to prevent non-specific sticking of antibody and ${ }^{125}$ I-labeled staphylococcal protein A $(\mathrm{SpA})$ to the membrane or plate. Viable tissue cultured target cells, washed three times or more with PBS, are resuspended in DRIB buffer at a concentration of $10^{7}$ cells $/ \mathrm{ml} ; 3 \mu$ of this suspension is dotted onto the center of each test membrane (well). The antibody or supernatant to be tested is added to the well and allowed to incubate for $15 \mathrm{~min}$ at room temperature. The well is washed four times; each wash occurs by filling the well ( $>300 \mu 1$ ) with DRIB buffer, then emptying the well using the vacuum manifold designed for the plates (Millipore, Bedford, MA). In a modification of the previously described technique, after the fourth wash, $50 \mu \mathrm{l}$ of rabbit anti-mouse $\operatorname{IgG}$ diluted $1 / 100$ in DRIB buffer, is added to each test well. This reagent allows any subclass of mouse immunoglobulin binding to target cells to be detected using the ${ }^{125}$ I-labeled SpA used as a developing reagent. After $15 \mathrm{~min}$ of incubation at room temperature, the plate is then washed four times and $50 \mu 1$ of ${ }^{125}$ I-labeled SpA (NEN Research Products, Boston, MA) diluted to 50000 counts $/ \mathrm{ml}$, are added to each well. The plate is incubated for $15 \mathrm{~min}$ at room temperature, washed 6-8 times, and allowed to dry. The assay is evaluated quantitatively by autoradiographic exposure of XAR film (Kodak, Rochester, NY) for 6-12 h with development in an RPXOMAT developer, and quantitatively by punching out individual wells and counting the membrane in a gamma counter.

The whole-cell fluorescent immunoassay was performed using the screen machine (Pandex, Mundelein, IL). This computer-controlled instrument uses a special 96-well membrane-bottomed plate that is filled and washed automatically by a series of pipets within the machine. The wells are emptied by suction through the bottom of the plates using a vacuum line within the machine. The instrument is also capable of automatically adding reagents and following a user controlled protocol to wash the wells of the plates. The instrument has a specially designed fluorimeter capable of exciting and reading at several wavelengths (we used $489 / 515 \mathrm{~nm}$ ). In this assay, $20 \mu \mathrm{l}$ of a $1 \%$ solution of BSA-coated polystyrene beads. $3 \mu \mathrm{m}$ in diameter, were added automatically to the wells of the plate by the instrument. Then. 
20000-50000 washed viable tissue cultured cells were dotted onto the wells in a small volume; 50 $\mu 1$ of antibody or hybridoma supernatant are added. These latter two steps were usually performed manually in this laboratory to reduce the number of cells required for assay. The instrument is capable of adding any reagent that is added to a number of wells but the reservoir has a relatively large $(2 \mathrm{ml})$ deadspace. This mixture was incubated for $15 \mathrm{~min}$ at room temperature within the instrument. The wells were then subject to a vacuum through a small port on the side of the plate. This process removes the liquid material in the well. The wells were then washed with PBS (50 $\mu 1 /$ well) by the instrument. The wash material was removed by vacuum and $50 \mu 1$ of FITC-conjugated goat or rabbit anti-mouse $\operatorname{IgG}, \mathrm{A}$ and $\mathrm{M}$ diluted $1 / 100$ in $2 \%$ BSA in PBS and filtered through a $0.22 \mu \mathrm{m}$ filter immediately prior to use, was added automatically by the instrument. The plates were incubated for $15 \mathrm{~min}$ at room temperature, and then the plates were subjected to vacuum within the instrument. The plates were then washed with $50 \mu 1$ of PBS/well and read in the fluorimeter in the instrument at the FITC settings $(489 / 515 \mathrm{~nm})$.

\section{Results}

\section{Optimization of the fluorescent assay}

First evaluated was the ability to use the assay with whole cells to determine whether the vacuum used by the instrument (which can be selected as high or low) would allow the cells to remain intact and viable. To evaluate this property, cells were stained with fluorescein diacetate (FDA). These cells will retain the FDA if they remain intact and viable (Rotman and Papermaster, 1966). However, once the cells dry, the FDA may leak if the cells are washed again (Jones and Senft, 1985). Several experiments were performed with different cell lines. If the assay is performed without beads, the viability drops significantly (data not shown). Also, the vacuum is considerably less effective if the beads are not used. The fluorimeter is not accurate if the wells are not completely dry, so the inability to completely evacuate the wells in the absence of the beads is a significant drawback. Occasionally

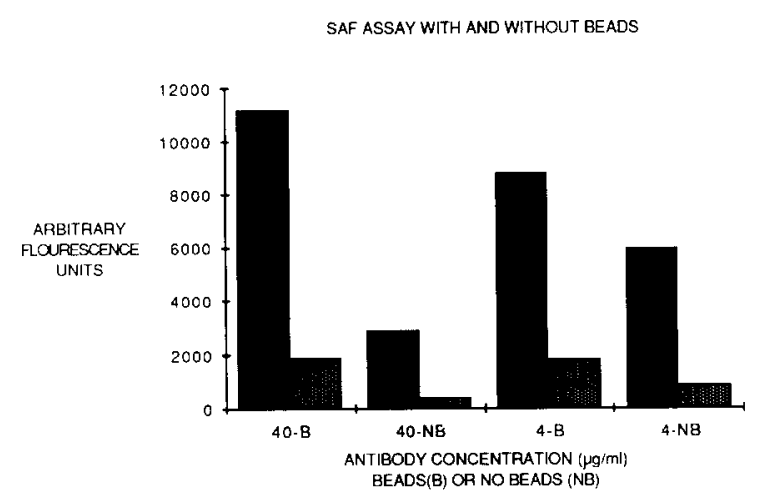

Fig. 1. SAF assay performed using HTB 63 human melanoma cells and anti-melanoma monoclonal antibody $225.28 \mathrm{~s}$, with and without beads. Specific reactivity is shown by solid bars and background (reaction without cells) is shown by shaded bars.

wells would not empty entirely even when beads were used. This problem occurred sporadically and may be a quality control problem with the plates. The assay is more sensitive in the presence of the beads, as shown in Fig. 1. The assay performed with the beads gives a much higher reading, although the background is also somewhat higher. We have found that use of the beads results in greater sensitivity and reproducibility. All of the rest of the results shown are with beads.

Other parameters evaluated with the assay were: use of several washes (no difference with one compared to two or three); and different volumes of washes (no difference between $20 \mu 1$ compared to $50 \mu \mathrm{l}$ ). Filtering the FITC-conjugated antibody was found to be very important in reducing background fluorescence, possibly due to aggregates. However, blocking the plates with BSA prior to assay did not reduce non-specific sticking or fluorescence background, in contrast to the effect of pre-blocking in the DRIB assay (Stya et al., 1984).

\section{Comparison of DRIB and $S A F$}

The SAF assay was compared using similar reagents to the DRIB and the results are shown in Fig. 2. The assay was performed with HTB 77 (human ovarian cancer cells) as the target cells, and $5 \mathrm{G} 6$ and UPC-10 as the positive and negative control antibodies, respectively. In both assays, the background is evaluated both by using a negative control antibody and by testing wells receiv- 
Fig. 2. Comparison of SAF and DRIB assays with HTB 77 human ovarian cancer cells, with anti-ovarian cancer monoclonal antibody 5G6.4 ( $A$ and $C$ ) and non-specific (control) monoclonal antibody UPC-10 ( $B$ and $D$ ). Specific reactivity is shown by solid bars, and non-specific reactivity (background, reaction without cells present) by shaded bars. In $A$ and $B, \mathrm{~B}$ on the $x$-axis represents reactivity with cells but without primary antibody.

A

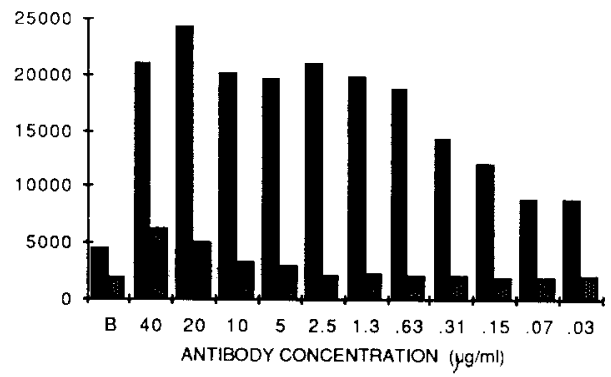

SAF-UPC 10 HTB 77 CELLS

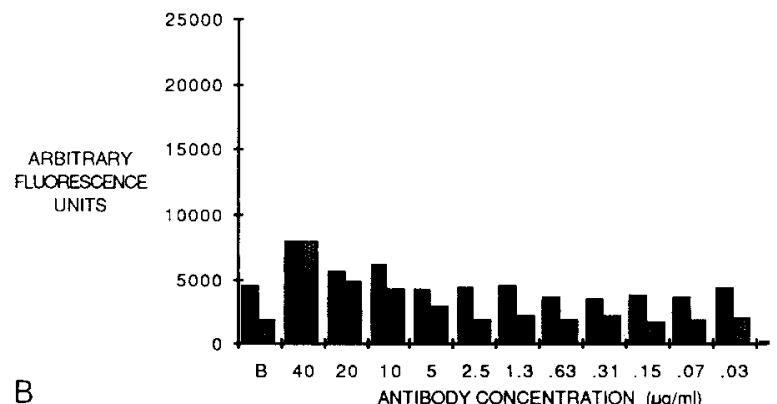

DAIB 5 G6.4 HTB 77 CELLS

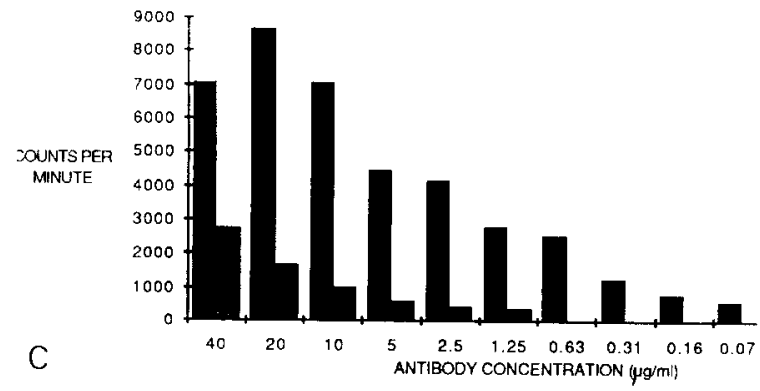

DAIB UPC 10 HTB 77 CELLS

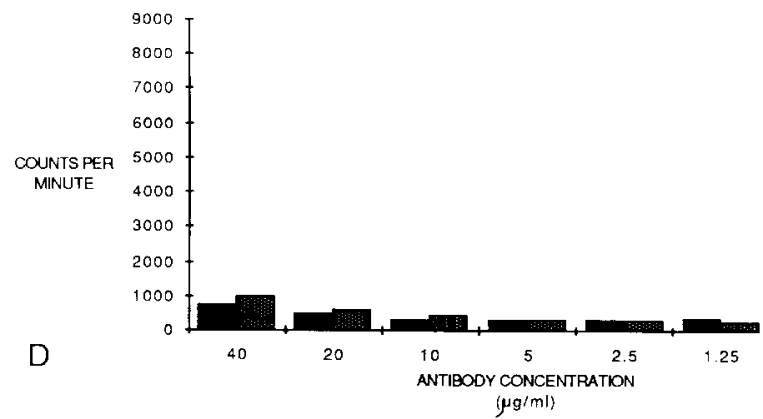

ing all reagents but without target cells. The SAF assay is quite comparable to the DRIB by comparison of fig. $2 A$ and $2 C$. The SAF assay may in fact be more sensitive at lower concentrations of antibody (below $0.3 \mu \mathrm{g} / \mathrm{ml}$ ). The SAF assay does have more background reactivity that can be seen in both Figs. $2 A$ and $2 B$. The lower (but still observable) reactivity with UPC-10, above the background reading for those wells, indicates the background problem with the assay. This problem is not seen with the DRIB assay as shown in Fig.

TABLE I

COMPARISON OF PROTOCOLS AND TIME REQUIRED FOR DRIB AND SAF ASSAYS

\begin{tabular}{|c|c|c|c|c|}
\hline DRIB & $\begin{array}{l}\text { Time } \\
\text { elapsed } \\
\text { (min) }\end{array}$ & SAF & $\begin{array}{l}\text { Time } \\
\text { elapsed } \\
\text { (min) }\end{array}$ & $\begin{array}{l}\text { Auto- } \\
\text { mation }\end{array}$ \\
\hline $\begin{array}{l}\text { Block plate } \\
\quad(2-12 \mathrm{~h})\end{array}$ & 120 & Add beads & 5 & : \\
\hline $\begin{array}{l}\text { Dot on target } \\
\text { cells }\end{array}$ & 5 & Add target cells & 10 & h \\
\hline $\begin{array}{l}\text { Add test } \\
\text { antibody }\end{array}$ & 5 & $\begin{array}{l}\text { Add test } \\
\text { antibody }\end{array}$ & 5 & $\mathrm{~b}$ \\
\hline Incubate & 15 & Incubate & 15 & \\
\hline Wash $4 \times$ & 15 & Wash $1 \times$ & 8 & $a$ \\
\hline $\begin{array}{l}\text { Add rabbit, } \\
\text { anti-mouse IgG }\end{array}$ & 5 & $\begin{array}{l}\text { Add FITC- } \\
\text { labelled goat, } \\
\text { anti-mouse IgG }\end{array}$ & 5 & a \\
\hline Incubate & 15 & Incubate & 15 & \\
\hline $\begin{array}{l}\text { Wash } 4 \times \\
\text { Add }^{125} \text { I-SpA }\end{array}$ & 15 & Wash $1 \times$ & 8 & it \\
\hline incubate & 15 & & & \\
\hline Wash $6-8 \times$ & 20 & & & \\
\hline $\begin{array}{l}\text { Dry (90 Min } \\
\text { overnight) }\end{array}$ & 90 & & & \\
\hline $\begin{array}{l}\text { Exposure to } \\
\text { X-ray film } \\
\text { read results }\end{array}$ & 360 & $\begin{array}{l}\text { Read, review } \\
\text { results }\end{array}$ & 11 & a \\
\hline Total time & 680 & & 82 & \\
\hline
\end{tabular}

Routinely automated.

${ }^{b}$ Capable of automation, not routinely done. 
$2 D$, where 'test' reactivity is less than the background reactivity (clearly negative). Thus, the SAF assay needs to be evaluated not only for background reactivity but also to be compared to a baseline activity in media and buffer controls. In the DRIB, we routinely use a response to background ratio of 5 as a cut-off to determine which cells will be saved. With the SAF assay, more interpretation is needed.

\section{Time evaluation}

Table I shows a side-by-side comparison of the DRIB and SAF assays for steps, automation, and time comparisons. The SAF assay can be performed in less than $2 \mathrm{~h}$ with minimal operator involvement, even with the manual steps we perform. The DRIB assay requires significant technician intervention at each step (except for incubations), more washing, longer development time, and requires a minimum of $11 \mathrm{~h}$ to get results.

\section{Ascites evaluation}

Production of antibodies in ascites over time should be checked periodically for good antibody activity, since antibody production by the cells in the ascites may drop over time (Goding, 1980; Eshhar, 1985). In testing ascites, we observed that the usual dilution used in the DRIB $(1 / 100)$ gave unacceptably high background in the SAF assay, but that dilution of $1 / 1000$ or greater resulted in good reactivity over background in the SAF (see Fig. 3) and can be used to evaluate antibody production in ascites.

\section{G10.1 ASCITES}

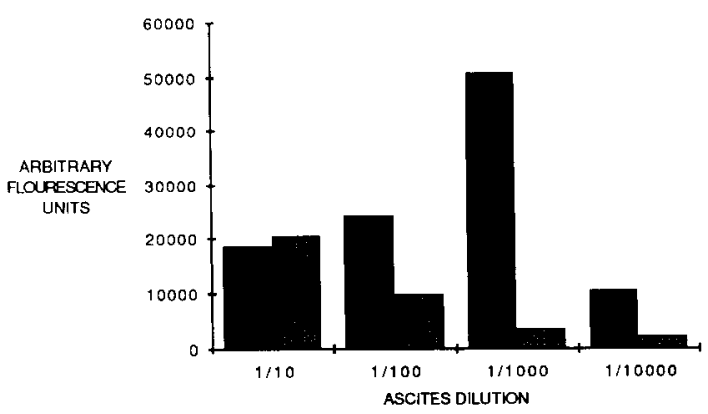

Fig. 3. Ascites testing of $6 \mathrm{~g} 10$ anti-small cell carcinoma monoclonal antibody with NCI 69 small carcinoma cell. Specific reaction is shown by solid bars, and background (reaction without cells) is shown by shaded bars.

\section{Discussion}

This paper reports the development and use of a fluorescence assay with whole live cells that can be automated. The assay described here is similar to the 'Cell-FLISA' assay (Okumura et al., 1986), but differs in the use of the automating instrument and the use of membrane-bottomed plates. As previously reported, the use of membrane-bottom plates provides ease of access for more effective washing (Glassy et al., 1983; Stya et al., 1984). The cells remain viable and intact through the first separation step, which is important in screening selectively for antigens on the cell surface. Although the use of the Pandex screen machine has been reported for particle assays (Jolly et al., 1984; Mayus et al., 1986), this is the first report of the use of this system with whole, viable target cells.

The automation of this fluorescence assay results in a test turn-around time and sensitivity comparable to that reported for ELISA. In comparison to the DRIB, the SAF assay is significantly faster, and requires very little operator involvement once the plate is set up.

We have shown that the SAF assay is useful for screening of hybridomas, is sensitive, rapid, gives results comparable to the DRIB, can be used to monitor antibody production in ascites, and is automated. The use of this assay results in a significant labor reduction in the screening and maintenance of hybridomas.

\section{References}

Eshhar, Z. (1985) Monoclonal antibody strategy and techniques. In: T.A. Springer (Ed.), Hybridoma Technology in the Biosciences and Medicine (Plenum Press, New York) p. 3.

Ey, P.L., Prowse, S.J. and Jenkin, C.R. (1970) Isolation of pure IgG1, IgG2a and IgG2b immunoglobulins from mouse serum using protein A-Sepharose. Immunochemistry 15, 429.

Furst, A. and Mahowald, A.P. (1984) Rapid immunofluorescent screening procedure using primary cell cultures or tissue sections. J. Immunol. Methods 70, 101.

Glassy, M.C., Handley, H.H., Cleveland, P.H. and Royston, I. (1983) An enzyme immunofiltration assay useful for detecting human monoclonal antibody. J. Immunol. Methods 58, 119. 
Goding, J.W. (1980) Antibody production by hybridomas. J. Immunol. Methods 39, 285.

Hough, T., Singh, M.B., Smart, I.J. and Knox, R.B. (1986) Immunofluorescent screening of monoclonal antibodies to surface antigens of animal and plant cells bound to polycarbonate membranes. J. Immunol. Methods 92, 103.

Howard, F.D., Ledbetter, J.A. Mehidi, S.Q. and Herzenberg. L.A. (1980) A rapid method for the detection of antibodies to cell surface antigens: a solid phase radioimmunoassay using cell membranes. J. Immunol. Methods 38, 75.

Jolley, M.E., Wang, C.J., Ekenberg, S.J., Zuelke, M.S. and Kelso, D.M. (1984). Particle concentration fluorescence immunoassay (PCFIA): a new, rapid immunoassay technique with high sensitivity. J. Immunol. Methods 67, 21.

Jones, K.H. and Senft, J.A. (1985) An improved method to determine cell viability by simultaneous staining with fluorescein diacetate-propidium iodide. J. Histochem. Cytochem. 33, 77.

Kennett, R.H. (1980) In: R.H. Kennett, T.J. McKearn and K.B. Bechtol (Eds). Monoclonal Antibodies and Hybridomas: A New Dimension in Biological Analysis (Plenum Press. New York) p. 376.

Mayus, J., Macke, K., Shackelford, P., Kim, J. and Nahm, M. (1986) Human IgG subclass assays using a novel assay method. J. Immunol. Methods 88,65 .
Okumura, N., Aosai, F., Yui, K., Yamashita, K.. Yabu, K. Kanai, M. and Yano, A. (1986) Cellular FITC-linked immunospecific assay (Cell-FLISA) for detection of monoclonal antibodies against cell-surface antigens. Hum. Immunol. 15, 97.

Rotman. B. and Papermaster, B.W. (1966) Membrane properties of living mammalian cells as studies by enzymatic hydrolysis of fluorogenic esters. Proc. Natl. Acad. Sci. U.S.A. 55, 134.

Stya, M., Wahl, R. and Beierwaltes, W.H. (1984) Dot-based ELISA and RIA: two rapid assays that screen hybridoma supernatants against whole live cells. J. Immunol. Methods 73,75 .

Wahl, R.L., Liebert, M., Biesman, B., Roberts, J., Jackson, G., Kronberg, S. and Laino, L. (1986) Production and characterization of a murine monoclonal antibody reactive with ovarian and other epithelial carcinomas. Proc. Am. Assoc. Cancer Res. 27, 355.

Wilson, B.S., Ruberto, G. and Ferrone, S. (1983) Immunochemical characterization of a human high molecular weight-melanoma associated antigen identified with monoclonal antibodies. Cancer Immunol. Immunother. 14, 196. 